\title{
A importância dos bancos públicos no enfrentamento aos impactos da Covid-19 no Brasil: elementos para debate ${ }^{1}$
}

The role of public banks facing the impacts of Covid-19 in Brazil: elements for debate

Daniel Pereira Sampaio ${ }^{2}$

Rafael da Silva Barbosa ${ }^{3}$

Resumo: $\mathrm{O}$ artigo tem por objetivo realizar um estudo sobre a função social dos bancos públicos e sua importância no enfrentamento aos impactos econômicos decorrentes da pandemia do Covid-19 no Brasil. A partir da perspectiva pós-keynesiana sobre bancos públicos, analisa-se a evolução recente da dinâmica bancária brasileira, sobretudo de sua maior capilaridade física regional a partir dos dados do Banco Central do Brasil. A conclusão é que além de maior cobertura no território, os bancos públicos agem de maneira a amenizar as flutuações cíclicas devido a sua função social, sendo assim, possuem elevada importância para as políticas públicas de enfrentamento ao Covid-19.

Palavras-chave: Bancos públicos. Covid-19. Política econômica.

Abstract: The article aims to study the social function of public banks and their importance in facing the economic impacts of the Covid-19 pandemic in Brazil. Based on the post-Keynesian perspective on public banks, it analyses the recent evolution of the Brazilian banking dynamics, especially its largest regional capillarity based on data from the Brazilian Central Bank. It concludes that in addition to their larger coverage in the territory, public banks act in such a way as to attenuate cyclical fluctuations due to their social function, and thus have high importance for public policies to face the Covid-19.

Keywords: Economic policy. Covid-19. Public banks.

\footnotetext{
${ }^{1}$ Uma versão preliminar deste artigo foi publicada no portal "Brasil Debate".

2 Economista, doutor em Desenvolvimento Econômico (IE-UNICAMP), professor do Departamento de Economia e do Programa de Pós-Graduação em Política Social da Universidade Federal do Espírito Santo (UFES). Contato: daniel.sampaio@ufes.br.

${ }^{3}$ Economista, doutor em Desenvolvimento Econômico (IE-UNICAMP), realiza estágio pós-doutoral em Política Social na Universidade Federal do Espírito Santo (UFES) e é colunista do Brasil Debate. Contato: rafael.econ@gmail.com.
} 


\section{Introdução}

A pandemia da Covid-19, causada pelo vírus SarsCov2, traz desafios tanto nos campos sanitários, científicos e tecnológicos, na corrida por uma cura, quanto nos campos político, econômico e social. Em junho de 2020, a Organização para a Cooperação e Desenvolvimento Econômico (OCDE) divulgou previsões alarmantes para o crescimento econômico, saúde, bem-estar e relações de trabalho, situação agravada pela pandemia. Em termos de crescimento, vislumbra-se a pior recessão do século com queda estimada, caso se evite uma segunda onda de contaminação, em 6\% do Produto Interno Bruto (PIB) mundial. Ainda neste melhor cenário, a previsão do crescimento do PIB dos Estados Unidos é de -7,3\%, de -2,6\%, na China, e de -7,4\%, no Brasil (OCDE, 2020).

A crise econômica e social agravada pela pandemia tem levantado a necessidade de ação estatal para seu enfrentamento por meio do aumento do gasto público. Contudo, a Organização das Nações Unidas para o Comércio e Desenvolvimento (UNCTAD) reportou, em março de 2020, que dos US\$ 5 trilhões mapeados dos programas de ajuda governamentais no mundo apenas um quarto deles seria efetivo para a manutenção do emprego e da renda da população (UNCTAD, 2020). No Brasil, as ações de política econômica encontram-se ainda limitadas, por exemplo, na aprovação do "Orçamento de Guerra”4, na facilitação do crédito dos bancos públicos e no Auxílio Emergencial5.

Como um braço do Estado para a realização de políticas econômicas e sociais, pergunta-se: como os bancos públicos (federais, regionais ou estaduais) podem contribuir para combater impactos econômicos e sociais decorrentes da Covid-19? Para responder a essa questão, o presente artigo divide-se em duas seções além desta introdução e das considerações finais. $\mathrm{Na}$ primeira seção, discute-se a importância dos bancos públicos no processo de desenvolvimento capitalista no Brasil. Em seguida, busca-se analisar o campo de ação dos bancos públicos, especialmente no quesito cobertura física dos bancos estaduais ainda existentes.

\section{A importância dos bancos públicos no processo de desenvolvimento capitalista no Brasil}

Os bancos públicos historicamente tiveram papel relevante no desenvolvimento brasileiro, sendo fundamentais no enfrentamento dos desafios colocados pelo avanço das relações de produção e da utilização de meios de troca (numerários) nas relações econômicas, sejam elas de compensação bancária, de intermediação financeira ou do financiamento ao desenvolvimento (COSTA, 2014). Os

\footnotetext{
${ }^{4}$ Que flexibiliza a meta orçamentária enquanto durar o estado de calamidade pública.

${ }^{5}$ Respectivamente, Emenda Constitucional no 106/2020, Medida Provisória no 958/2020 e Medida Provisória no 936 e $937 / 2020$.

\begin{tabular}{|l|c|c|c|c|c|c|c|c}
\hline Cadernos de Ciências Sociais Aplicadas & ano XVII & vol. 17 & $n^{\circ} 30$ & págs. 160-171 & jul./dez: 2020 & UESB & Vitória da Conquista/BA & pág. 161 \\
\hline
\end{tabular}
}


bancos públicos fazem chegar à população políticas sociais coordenadas pelo Estado, como o Fundo Garantidor do Tempo de Serviço (FGTS), o programa Bolsa Família e o atual Auxílio Emergencial. Além disso, respondem de forma mais rápida às crises financeiras, como a de 2008 (IPEA, 2010) e a atual, tendo importante contribuição para a manutenção do circuito crédito-renda em funcionamento da economia nacional.

Em termos teóricos, essas funções dos bancos públicos são apreendidas pela teoria póskeynesiana que afirma que os bancos públicos federais apresentam as seguintes funções: fomentam o desenvolvimento econômico e regional; direcionam crédito para regiões e setores específicos; possuem ação anticíclica; e contribuem para o aumento da taxa de bancarização da população brasileira (ARAÚJO; CINTRA, 2011).

O Banco do Brasil (BB) foi fundado pouco tempo após a chegada da família Real, em 1808. Em 1861, foi fundada a Caixa Econômica Federal (CEF), com o objetivo inicial de captar poupança das camadas mais baixas para financiar programas sociais (COSTA, 2014). Já o Banco Nacional de Desenvolvimento Econômico e Social (BNDES) foi criado a partir da Comissão Mista Brasil-Estados Unidos, em 1952, com o objetivo de prover condições de financiamento de longo prazo, para a continuidade do processo de industrialização (PAIVA, 2012). Esses três bancos públicos federais foram peças indispensáveis para a promoção e financiamento da diversificação produtiva e o alargamento do mercado de trabalho e do leque de empregos, mesmo que de forma desigual e combinada no território ${ }^{6}$. Seus papeis variaram no tempo e no espaço, a depender das necessidades do desenvolvimento capitalista ${ }^{7}$, bem como das articulações entre Estado e mercado.

Atualmente, em relação à política de crédito, o BB tem papel relevante na oferta de crédito rural, a CEF no crédito imobiliário e o BNDES no financiamento à indústria e à infraestrutura econômica (IPEA, 2010). Em última instância, o Banco do Brasil, como banco comercial, serve como um "farol" do setor bancário, atuando como um parâmetro à qualidade no processo de concorrência do setor bancário brasileiro. E a CEF atua também como banco comercial, mas orientada também às necessidades do trabalhador como agente responsável pelo Fundo de Garantia por Tempo de Serviço (FGTS), Programa de Integração Social (PIS) e Seguro-Desemprego (programas relevantes ao trabalhador com carteira assinada), além de ser operador do Programa Bolsa Família e do atual Auxílio Emergencial.

\footnotetext{
${ }^{6}$ A historicidade do processo de desenvolvimento desigual e combinado no Brasil é tema de múltiplas obras, das quais se destacam Becker e Egler (1993), Tavares (1999), Brandão (2007) e Cano (2017).

${ }^{7}$ Por exemplo, o BB já atuou com funções típicas de um Banco Central antes de sua criação no Brasil. O BNDES já atuou como peça importante no processo de privatizações, principalmente na década de 1990. A CEF incorporou a função de crédito imobiliário do Banco Nacional de Habitação (BNH) após a sua extinção em 1986 (COSTA, 2014). \begin{tabular}{l|l|l|l|l|l|l|l|l|l}
\hline Cadernos de Ciências Sociais Aplicadas & ano XVII & vol. 17 & $n^{\circ} 30$ & págs. 160-171 & jul./der: 2020 & UESB & Vitória da Conquista/BA & pág. 162 \\
\hline
\end{tabular}
} 
Diante dos desequilíbrios regionais que historicamente marcaram a formação econômica e regional brasileira, também foram criados bancos regionais e estaduais, tanto com caráter comercial ${ }^{8}$ quanto de desenvolvimento9 ${ }^{9}$, com o objetivo de diminuir as desigualdades regionais (COSTA, 2014). Os bancos públicos federais, regionais ou estaduais conseguem atingir regiões remotas ou periféricas, ao longo de nossa extensão territorial, que, por vezes, dado o baixo dinamismo econômico, não são atrativas ao setor privado. Assim, contribuem para a pulverização no território do acesso aos mais diversos serviços ofertados, independente da posição na estratificação social, numa determinada sociedade que se organizou sob o fetiche do dinheiro e da propriedade privada.

Ao longo dos últimos trinta anos, muitos dos bancos públicos regionais foram extintos ou privatizados ${ }^{10}$, o que contribuiu para o aumento da concentração bancária no país. Mas, a sobrevivência dos poucos que ficaram pode revelar suas funções sociais diante dos atuais desafios colocados por uma crise sanitária global, imposta pela pandemia.

\section{Bancos públicos e políticas voltadas ao enfrentamento dos impactos da Covid-19}

Em que pese a elevada concentração bancária no Brasil, a demanda por crédito não se coloca plenamente satisfeita pelos mecanismos de mercado do setor privado. Nesse sentido, o sistema financeiro, principalmente o privado, coloca-se como uma trava ao desenvolvimento econômico (DOWBOR, 2015). Por isso, a principal função social dos bancos públicos no Brasil é, para além de promover serviços de intermediação financeira, atender de forma técnica as necessidades prementes da população.

Os impactos econômicos e sociais provocados pela atual crise sanitária global vieram mostrar, entre outras, a importância da capacidade instalada das agências bancárias no território brasileiro, por exemplo, na operacionalização do atual programa de Auxílio Emergencial realizado por intermédio da CEF. A expertise da CEF no trato com programas sociais do governo federal, bem como a cobertura

\footnotetext{
8 Por exemplo, os ainda existentes Banco do Estado o Pará (BANPARÁ), o Banco do Estado de Sergipe (BANESE), o Banco do Estado do Espírito Santo (BANESTES) e o Banco do Estado do Rio Grande do Sul (BANRISUL).

9 Tais como os ainda existentes Banco do Nordeste (BNB), o Banco da Amazônia (BASA), o Banco de Desenvolvimento do Espírito Santo (BANDES).

10 Sobre o processo de privatizações no Brasil, recomenda-se Landi (2009).

\begin{tabular}{l|l|l|l|l|l|l|c|c}
\hline Cadernos de Ciências Sociais Aplicadas & ano XVII & vol. 17 & $n^{\circ} 30$ & págs. 160-171 & jul./der. 2020 & UESB & Vitória da Conquista/BA & pág. 163 \\
\hline
\end{tabular}
}


da rede de agências bancárias, garante maior possibilidade de acesso e de diminuição nos deslocamentos, evitando-se aglomerações especialmente para famílias de baixa renda ${ }^{11}$.

O Banco Central do Brasil (BACEN) divulga periodicamente estatísticas referentes ao setor bancário e financeiro brasileiro. Em função da mudança na metodologia das estatísticas em meados de 2016, buscou-se construir a Tabela 1 para assimilar o efeito real da trajetória do número de agências bancárias. Assim, tornou-se possível fazer uma leitura tanto do método anteriormente aplicado quanto da recente metodologia, com a inclusão de outros estabelecimentos do sistema financeiro não-bancário. Ademais, foi possível apresentar duas categorias: (1) a "contínua", representativa da atual divulgação realizada pelo Banco Central; (2) a "ajustada", executada com base na antiga metodologia, caso não tivessem ocorrido mudanças.

Tabela 1 - Quantidade de Instituições e Agências Bancárias (unidades)

\begin{tabular}{cccccccc}
\hline Tipo & Série & $\mathbf{2 0 0 7}$ & $\mathbf{2 0 1 0}$ & $\mathbf{2 0 1 3}$ & $\mathbf{2 0 1 6}$ & $\mathbf{2 0 1 9}$ & 2020* \\
\hline \multirow{2}{*}{ Instituições } & Contínua & 154 & 157 & 156 & 553 & 522 & 523 \\
& Ajustada & 154 & 157 & 156 & 164 & 154 & 154 \\
& Contínua & 18.361 & 19.647 & 22.705 & 23.539 & 20.937 & 20.580 \\
\multirow{2}{*}{ Agências } & Ajustada & 18.361 & 19.647 & 22.705 & 22.651 & 20.195 & 19.883
\end{tabular}

Fonte: Banco Central do Brasil. Elaboração própria.

*Dados de abril de 2020.

O número de instituições e agências bancárias cresceu consideravelmente entre 2007 e 2016, com 5,57 mil novas unidades na série "contínua" e 4,30 mil novas unidades na série "ajustada" (Tabela 1), o que representa $23,2 \%$ de expansão nesta última série e demonstra o movimento da expansão da rede bancária. Entre 2016 e 2020, houve uma redução de 12,2\% do número de agências bancárias na série "ajustada", o que pode estar relacionado tanto ao baixo dinamismo econômico, às perdas sociais do período, bem como à opção política de diminuição do papel do Estado na economia, via políticas de austeridade fiscal.

\footnotetext{
${ }^{11}$ Em muitos casos, o acesso ao transporte coletivo, por ser mercantilizado, acaba por ser um impeditivo do acesso de famílias de baixa renda aos núcleos urbanos, por conseguinte, ao acesso à rede bancária. Por isso, nos termos de Harvey (2012), o acesso ao transporte coletivo pode ser um impeditivo ao "direito à cidade". \begin{tabular}{|l|c|c|c|c|c|c|c|c|}
\hline Cadernos de Ciências Sociais Aplicadas & ano XVII & vol. 17 & $n^{\circ} 30$ & págs. $160-171$ & jul./der: 2020 & UESB & Vitória da Conquista/BA & pág. 164 \\
\hline
\end{tabular}
} 
Entre 2007 e 2016, o número de agências bancárias do BB e da CEF cresceram, respectivamente, 34,3\% e 66,7\%. Já entre 2016 e 2020, houve uma redução do número, respectivamente, de 19,6\% e 1,1\%. Dos bancos privados, o Bradesco teve pequena redução do número de agências entre 2016 e 2020, o Itaú encolheu abruptamente e o Santander teve pequeno crescimento (Tabela 2).

Tabela 2 - Número de agências das cinco maiores instituições bancárias* no Brasil (unidades)

\begin{tabular}{ccccccc}
\hline $\begin{array}{c}\text { Instituições } \\
\text { bancárias }\end{array}$ & $\mathbf{2 0 0 7}$ & $\mathbf{2 0 1 0}$ & $\mathbf{2 0 1 3}$ & $\mathbf{2 0 1 6}$ & $\mathbf{2 0 1 9}$ & $\mathbf{2 0 2 0 * *}$ \\
\hline $\begin{array}{c}\text { Banco do Brasil } \\
\text { Caixa Econômica } \\
\text { Federal }\end{array}$ & 4.042 & 5.035 & 5.416 & 5.430 & 4.303 & 4.368 \\
Bradesco & 2.046 & 2.097 & 3.175 & 3.411 & 3.374 & 3.372 \\
$\quad 3.043$ & 3.465 & 4.673 & 4.481 & 4.563 & 4.396 \\
Itaú & 3.435 & 3.635 & 3.875 & 3.541 & 3.136 & 2.965 \\
Santander & 2.180 & 2.305 & 2.630 & 2.655 & 2.715 & 2.745
\end{tabular}

Fonte: Banco Central do Brasil. Elaboração própria.

*Em 2008, o Itaú fez uma fusão com Unibanco, por isso, para 2007, foi somado as agências das duas instituições de 2.505 e 930, respectivamente, resultando num total de 3.435. Em 2008, o Santander fez uma fusão com ABN AMRO Real S.A., por isso, para 2007, foi somado as agências das duas instituições de 1.111 e 1.069 , respectivamente, resultando num total de 2.180 . ** Dados de abril de 2020 .

Dentre o número de agências dessas cinco principais instituições bancárias, 45,3\% eram de bancos públicos em 2016, o que foi reduzido para 43,4\% em 2020. Essa modificação pode estar relacionada com processo de reestruturação bancária pública marcada pelo avanço das políticas de austeridade ${ }^{12}$.

\footnotetext{
${ }^{12}$ Além disso, percebe-se a presença na presidência do Banco Central do Brasil de figuras ligadas a esses principais bancos privados. Henrique Meirelles, historicamente ligado ao BankBoston (cujos ativos no Brasil foram vendidos ao Itaú em 2006), dirigiu a instituição entre 2003 e 2010; Alexandre de Tombini, funcionário de carreira do Banco Central, presidiu a instituição entre 2011 e 2016, e , após este período, foi diretor do Fundo Monetário Internacional (FMI) e representante-chefe para as Américas no Banco Internacional de Compensações (BIS) ; Ilan Goldfajn, historicamente ligado ao Itaú, presidiu a instituição entre 2016 e 2019; e, Roberto Campos Neto, historicamente ligado ao Santander, é presidente desde 2019.

\begin{tabular}{|l|c|c|c|c|c|c|c|c}
\hline Cadernos de Ciências Sociais Aplicadas & ano XVII & vol. 17 & $n^{0} 30$ & págs. 160-171 & jul./dez: 2020 & UESB & Vitória da Conquista/BA & pág. 165 \\
\hline
\end{tabular}
}


No que tange ao alcance regional das cinco maiores instituições bancárias, a distribuição das agências dos bancos públicos federais é mais homogênea do que a do setor privado. Enquanto o setor público concentra $44,1 \%$ das suas agências bancárias no Sudeste, o setor privado concentra $60,7 \%$ no Sudeste, resultado que já demonstra maior desequilíbrio regional (Tabela 3).

Tabela 3 - Agências das cinco maiores instituições bancárias por região em 2020*

\begin{tabular}{|c|c|c|c|c|c|c|c|}
\hline \multicolumn{2}{|c|}{ Tipo } & NO & NE & SE & SUL & $\mathrm{CO}$ & Total \\
\hline \multirow{2}{*}{ Público } & unid. & 474 & 1.558 & 3.416 & 1.546 & 745 & 7.739 \\
\hline & $\%$ & 6,1 & 20,1 & 44,1 & 20,0 & 9,6 & 100,0 \\
\hline \multirow{2}{*}{ Privado } & unid. & 390 & 1.286 & 6.134 & 1.560 & 736 & 10.106 \\
\hline & $\%$ & 3,9 & 12,7 & 60,7 & 15,4 & 0,0 & 100,0 \\
\hline
\end{tabular}

Fonte: Banco Central do Brasil. Elaboração dos autores. *Dados de abril de 2020.

Assim, a cobertura da estrutura bancária pública potencializa melhor alcance das políticas sociais para o enfrentamento dos impactos econômicos decorrentes da Covid-19. Entre as políticas mais importantes, estão a ampliação do crédito, principalmente para micro e pequenas empresas, bem como o acesso a programas sociais.

Em vista dos impactos econômicos da atual crise sanitária, os bancos públicos são chamados para o front ${ }^{13}$ para fazer chegar à população medidas de política econômica frente um ambiente econômico mais incerto, como as políticas sociais e manutenção do circuito crédito-renda, com intuito de atenuar impactos sobre o emprego, renda, pobreza e miséria. Em vista da especificidade da crise instalada, a institucionalidade do crédito deve ser revista no sentido de buscar uma diminuição dos efeitos econômicos e de circulação monetária numa economia monetária da produção. À luz da função social dos bancos, os contratos de crédito na pandemia da Covid-19 devem satisfazer um tripé tanto na captação governamental do recurso quanto na sua distribuição (Quadro 1).

13 Tendo em vista que os bancos privados, por funcionarem sob mecanismos de mercado, são mais avessos ao risco num contexto mais incerto, dado um certa convenção sobre a realidade: "Para a efetivação de uma determinada ação, recorre-se a uma convenção, por exemplo, a de supor que a situação vigente continuará por um tempo indefinido, a não ser que existam razões concretas para se esperar uma mudança" (CARDOSO; LIMA, 2008, p. 374).

\begin{tabular}{|c|c|c|c|c|c|c|c|c|} 
Cadernos de Cièncias Sociais Aplicadas & ano XVII & vol. 17 & $n^{\circ} 30$ & págs. 160-171 & jul./der. 2020 & UESB & Vitória da Conquista/BA & pág. 166 \\
\hline
\end{tabular}




\section{Quadro 1 - Tripé dos contratos de crédito durante a pandemia Covid-19}

\begin{tabular}{|c|c|c|}
\hline 1. Finalidade & 2. Parâmetro & 3. Transparência \\
\hline $\begin{array}{l}\text { Os recursos devem ter por } \\
\text { finalidade objetivos } \\
\text { operacionais específicos } \\
\text { como amortização do capital } \\
\text { fixo e manutenção da mão de } \\
\text { obra, sendo vedada qualquer } \\
\text { operação financeira voltada a } \\
\text { ganhos pecuniários, como } \\
\text { lucro ou transferência de } \\
\text { débitos financeiros anteriores } \\
\text { ao contexto de pandemia ou } \\
\text { mesmo não condizentes com } \\
\text { as exigências operacionais do } \\
\text { momento. }\end{array}$ & $\begin{array}{l}\text { As condições dos contratos } \\
\text { devem ser regidas segundo } \\
\text { termos fixos, de maneira que os } \\
\text { preços em juros, spread e } \\
\text { inflação tenham baixo impacto } \\
\text { sobre a solvência do contrato. } \\
\text { Para tanto, tais parâmetros } \\
\text { devem se distanciar da lógica } \\
\text { de mercado, com vistas a evitar } \\
\text { taxas flutuantes e processos de } \\
\text { securitização que } \\
\text { desestabilizem tanto o credor } \\
\text { quanto o devedor e de modo } \\
\text { que se garanta uma gestão } \\
\text { estável dos papeis e facilitação } \\
\text { de seu acesso. }\end{array}$ & $\begin{array}{c}\text { Auditoria deve ser cláusula } \\
\text { obrigatória em todos os } \\
\text { contratos para garantir a } \\
\text { execução dos recursos de } \\
\text { acordo com os critérios de } \\
\text { "finalidade". O } \\
\text { desvirtuamento das } \\
\text { operações pode gerar baixa } \\
\text { efetividade dos resultados } \\
\text { esperados, com a criação de } \\
\text { bolhas especulativas, } \\
\text { inflação e apropriação } \\
\text { indevida do recurso } \\
\text { público. }\end{array}$ \\
\hline
\end{tabular}

Fonte: Elaboração própria.

O lastro dos contratos lança uma perspectiva maior, em que a crise pode se tornar uma oportunidade para se rever as políticas de austeridade. Assim, o país tem uma oportunidade histórica para o Estado retomar o protagonismo na coordenação do desenvolvimento, considerando o contexto das necessidades de ações, coordenações e capacidade de financiamento, ainda que nos moldes da financeirização. A retomada do protagonismo do Estado pode ser potencializada utilizando-se do arranjo federativo, especialmente em relação aos estados, por exemplo, com o Consórcio Nordeste. Uma política econômica e regional pode também produzir um legado positivo ao estimular uma reconversão industrial, de combate à desindustrialização, que atenda à demanda de saúde, educação, assistência social, transporte e outros serviços públicos.

No varejo, a existência de cinco bancos públicos estaduais ${ }^{14}$ é um elemento que pode fortalecer ainda mais o alcance da política econômica. Em termos de estrutura, o Banco Estadual do

\footnotetext{
${ }^{14}$ Cabe ressaltar a presença de bancos de desenvolvimento regionais e estaduais, como o Banco do Nordeste (BNB), o Banco da Amazônia (BASA), o Banco do de Desenvolvimento do Estado do Espírito Santo (BANDES) e o Bando de Desenvolvimento de Minas Gerais (BDMG).

\begin{tabular}{|l|c|c|c|c|c|c|c|c}
\hline Cadernos de Ciências Sociais Aplicadas & ano XVII & vol. 17 & $n^{\circ} 30$ & págs. 160-171 & jul./dez: 2020 & UESB & Vitória da Conquista/BA & pág. 167 \\
\hline
\end{tabular}
}


Pará (BANPARÁ), o Banco do Estado do Sergipe (BANESE) e o Banco de Brasília (BRB) possuem ampla cobertura (Figura 1.1, 1.2 e 1.5). Já o Banco do Estado do Espírito Santo (BANESTES) possui cobertura em todos os municípios, evidenciando dois núcleos de concentração. O primeiro na Região Metropolitana da Grande Vitória (RMGV) e o segundo no município Cachoeiro de Itapemirim, ao sul do Estado. Por último, o Banco do Rio Grande do Sul (BANRISUL) mostra presença na região Sul e, também, possui agências físicas em outros grandes centros urbanos como São Paulo, Rio de Janeiro e Brasília.

Figura 1 - Distribuição regional dos bancos públicos estaduais por município*

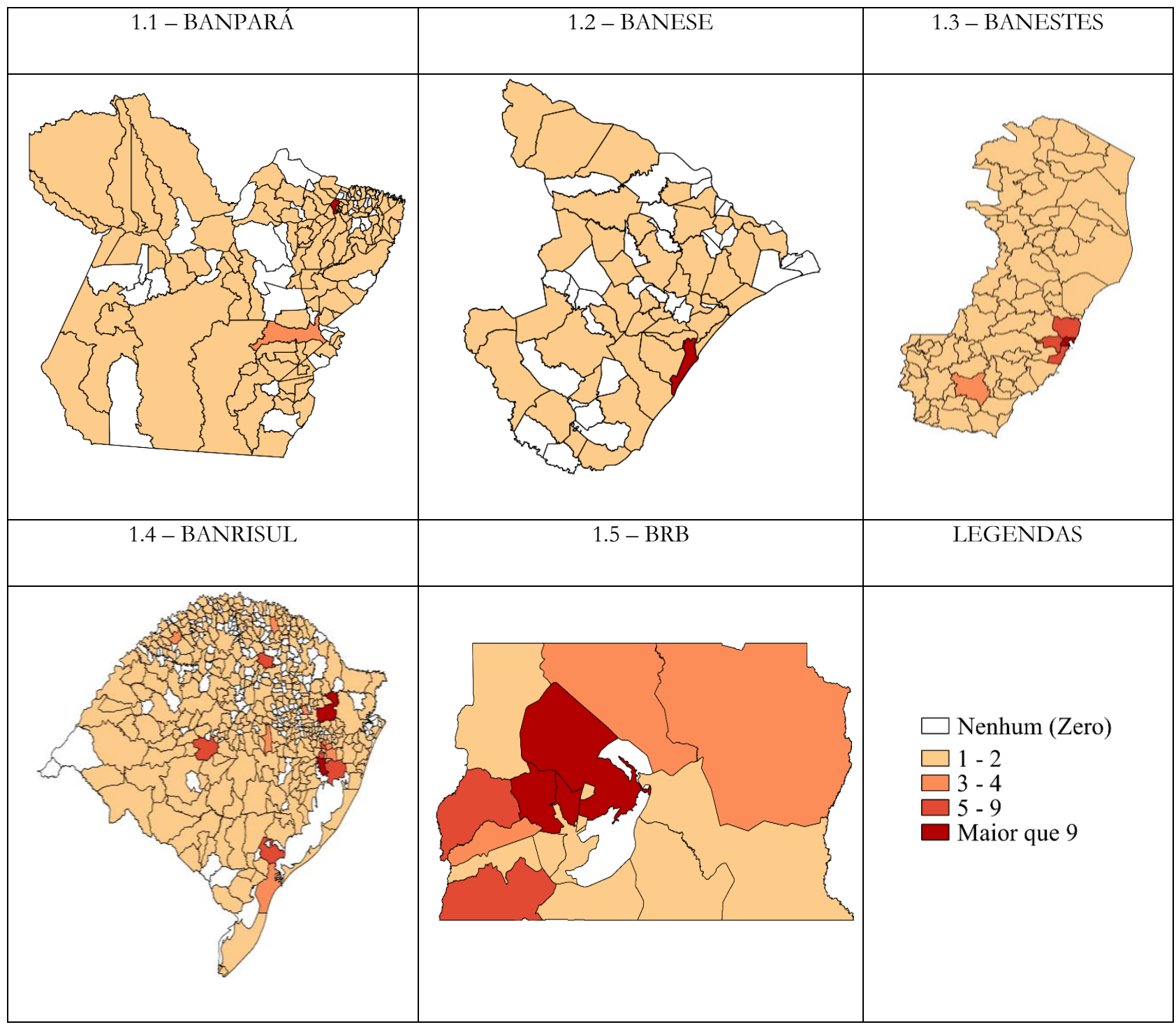

Fonte: Banco Central do Brasil. Elaboração própria com utilização do software Quantum Gis. * Brasília por subdistrito. 
Os dados sugerem que, do ponto de vista do varejo de serviços financeiros, a despeito da fragilização em curso nos últimos 30 anos, o Brasil possui estrutura, pessoal qualificado e capacidade de fomentar as relações de crédito adequada às exigências do momento. Todavia, parece faltar uma orientação mais ampla nesse sentido das autoridades governamentais, imbuídas em desmontar instituições estatais.

\section{Considerações finais}

Os bancos públicos cumprem quatro funções: (1) fomento ao desenvolvimento econômico e regional, como principal fornecedora de crédito de longo prazo; (2) ação para o combate a crises econômicas, fomentando a manutenção do circuito crédito-renda num contexto de elevação de incertezas e riscos; (3) acesso a benefícios sociais, como o Bolsa Família, Auxílio Emergencial e benefícios referentes ao emprego formal; (4) aumento da bancarização da população brasileira, principalmente na estratificação de baixa renda e no acesso a agências em regiões de mais baixo dinamismo econômico.

Em que pese o esforço de desmonte do Estado ao longo das últimas três décadas, ele ainda apresenta capacidade para ação nos diversos níveis federativos, tanto na capacidade de ação, quanto de coordenação, pois os bancos públicos são importantes atores para a execução de políticas econômicas e sociais e, sobretudo, para atenuação dos impactos econômicos derivados da atual pandemia.

Mesmo antes da Covid-19, a austeridade já não era um caminho adequado ao desenvolvimento nacional, implicando em baixo crescimento e pioras em indicadores sociais. $\mathrm{O}$ momento atual é uma oportunidade para correção de rumos. A inflexão drástica do modo de vida imposto pelo vírus demanda ações afirmativas do Estado nos diversos níveis federativos. Entretanto, o caminho escolhido pelas autoridades federais, até o momento, aponta para manutenção da agenda do antiquado instrumental neoliberal, que já provou sua insuficiência em vários momentos históricos.

\begin{tabular}{|l|c|c|c|c|c|c|c|c|c|}
\hline Cadernos de Ciências Sociais Aplicadas & ano XVII & vol. 17 & $n^{\circ} 30$ & págs. 160-171 & jul./dez: 2020 & UESB & Vitória da Conquista/BA & pág. 169 \\
\hline
\end{tabular}




\section{Referências}

ARAUJO, Victor Leonardo; CINTRA, Marco Antonio Macedo. O papel dos bancos públicos federais na economia brasileira. Texto para discussão, n. 1604, Brasília: IPEA, 2011. Disponível em:

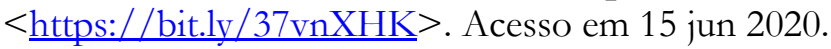

BECKER, Bertha K.; EGLER, Claudio A. G. Brasil: uma nova potência regional na economia mundo. Rio de Janeiro: Bertrand Brasil, 1994.

BRANDÃO, Carlos. Território e Desenvolvimento: as múltiplas escalas entre o local e o global. Campinas: Ed. UNICAMP, 2007.

CANO, Wilson. Brasil: construção e desconstrução do desenvolvimento. Economia e Sociedade, Campinas, v. 26, n. 2, p. 265-302, ago 2017. https://doi.org/10.1590/1982-3533.2017v26n2art1

CARDOSO, Fernanda G.; LIMA, Gilberto T. A concepção de Keynes do sistema econômica como um tudo orgânico complexo. Economia e Sociedade, Campinas, v. 17, n. 3, p. 359-381, dez 2008. https://doi.org/10.1590/S0104-06182008000300001

COSTA, Fernando Nogueira da. O Brasil dos Bancos. São Paulo: EdUSP, 2014.

DOWBOR, Ladislau. O sistema financeiro atual trava o desenvolvimento econômico. Estudos Avançados, São Paulo, v. 29, n. 83, jan-abr 2015. https://doi.org/10.1590/S0103$\underline{40142015000100013}$

HARVEY, David. O direito à cidade. Lutas Sociais, São Paulo, n. 29, p. 73-89, jul-dez 2012. https://revistas.pucsp.br/ls/article/view/18497

IPEA - INSTITUTO DE PESQUISA ECONÔMICA APLICADA. Bando do Brasil, BNDES e Caixa Econômica Federal: atuação dos bancos públicos federais no período 2003-2010.

Comunicados do IPEA, n. 105, Brasília: IPEA, 21 fls, 10 ago 2011. Disponível em: < https://www.ipea.gov.br/portal/images/stories/PDFs/comunicado/110810_comunicadoipea105.pd f>. Acesso em 18 jun 2020.

LANDI, Mônica. A evolução do Programa Nacional de Desestatização (PND): seus principais resultados e desdobramentos na infraestrutura. In: MARQUES, R.; FERREIRA, M. J. O Brasil sob a nova ordem: A economia brasileira contemporânea, uma análise dos governos Collor a Lula. São Paulo: Ed. Saraiva, 2009.

OCDE - ORGANIZAÇÃO PARA A COOPERAÇÃO E DESENVOLVIMENTO ECONÔMICO. OECD Economic Outlook, June 2020. Genebra: OCDE, junho 2020. Disponível em: < https://www.oecd.org/economic-outlook/june-2020/>. Acesso em 15 jun 2020.

PAIVA, Márcia de Paiva. BNDES: um banco de história e futuro. São Paulo: Museu da Pessoa, 2012. Disponível em: < https://web.bndes.gov.br/bib/jspui/handle/1408/1785>. Acesso em 18 jun 2020.

\begin{tabular}{l|l|l|l|l|l|l|c|c|}
\hline Cadernos de Cièncias Sociais Aplicadas & ano XVII & vol.17 & $n^{\circ} 30$ & págs. 160-171 & jul./der: 2020 & UESB & Vitória da Conquista/BA & pág. 170 \\
\hline
\end{tabular}


TAVARES, Maria da Conceição. Império, Território e Dinheiro. In: FIORI, J. L. (Org.). Estados e moedas no desenvolvimento das nações. Petrópolis: Ed. Vozes, pp. 449-489, 1999.

UNCTAD - ORGANIZAÇÃO DAS NAÇÕES UNIDAS PARA O COMÉRCIO E O DESENVOLVIMENTO. The Covid-19 shock to developing countries: Towards a "whatever it takes" programme for the two-thirds of the world's population being left behind. Genebra: UNCTAD, março 2020. Disponível em: <

https://unctad.org/en/PublicationsLibrary/gds tdr2019 covid2 en.pdf>. Acesso em 15 jun 2020.

Recebido em: junho de 2020

Aprovado em: julho de 2020 